\title{
Modelling UK household expenditure: economic versus non-economic drivers
}

\author{
Mona Chitnis ${ }^{\mathrm{a}}$ and Lester C. Hunt ${ }^{\mathrm{b}}$
}

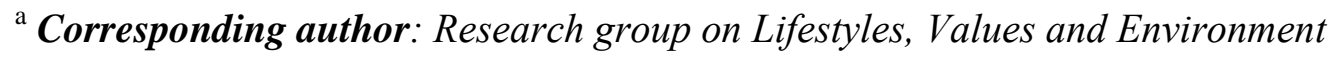
(RESOLVE) and Surrey Energy Economics Centre (SEEC), Centre for Environmental Strategy, University of Surrey, Guildford, Surrey, GU2 7XH, UK. Tel. +44 (0) 1483 682181, Fax. +44 (0) 1483 686671, E-mail:

\section{M.Chitnis@surrey.ac.uk}

${ }^{\mathrm{b}}$ Surrey Energy Economics Centre (SEEC) and Research group on Lifestyles, Values and Environment (RESOLVE), Department of Economics, University of Surrey,Tel.+44 (0) 1483 686956,E-mail: L.Hunt@surrey.ac.uk

This article attempts to quantify the contributions of economic and non-economic factors that drive UK consumer expenditure for 12 COICOP categories of goods and services using the Structural Time Series Model over the period 1964:q1-2006:q1. This approach allows for the relative quantification of the impact of non-economic factors on UK household expenditure demand (via a stochastic trend and stochastic seasonal) in addition to the economic factors (income and price). The results suggest that the contribution of the non-economic factors is generally higher for 'housing, water, electricity, gas and other fuels', 'health', 'communication' and 'education'; hence, they have an important role to play in these sectors. The message for policy makers is therefore that, in addition to economic incentives such as taxes which might be needed if they wish to restrain future expenditure, other policies that attempt to influence lifestyles might also need to be considered. 


\section{Introduction}

UK total real household expenditure (at 2003 prices) increased almost three fold from $£ 251 \mathrm{~m}$ in 1964 to $£ 720 \mathrm{~m}$ in 2005 , which debatably does not represent 'sustainable consumption'. There is therefore a need to understand better the structure of UK household expenditure, if policy makers wish to influence expenditure patterns and move towards more 'sustainable consumption'. To do this there is arguably a need to quantify, not only the key economic drivers of income and price, but also the non-economic factors such as technical progress, consumer taste and preferences, socio-demographic and geographic factors, lifestyle and value changes. Previous econometric work has generally concentrated on economic factors only, whereas a strand of the energy economics literature has focused on analysing non-economic factors, but there has not been an attempt, as far as is known, to bring these together and try to quantify their relative contributions to driving consumer expenditure. The aim here is therefore to quantify the relative contribution of economic and non-economic factors in determining UK household expenditure functions for $12 \mathrm{COICOP}{ }^{1}$ categories.

Many previous attempts have modelled UK household demand and expenditure (see Table 1 in Chitnis and Hunt, 2009a for a summary); although, only a few have

\footnotetext{
${ }^{1}$ 'Classification of Individual COnsumption by Purpose’, for more information see http://unstats.un.org/unsd/sna1993/glossform.asp?getitem=54.
} 
attempted to estimate demand or expenditure functions for separate COICOP categories, for example:

- Selvanathan and Selvanathan (2004) aggregated some of the 12 COICOP categories for South Africa and estimated $\mathrm{AIDS}^{2}$ and $\mathrm{CBS}^{3}$ functional forms for eight groups for 1960 to 1995 with no focus on non-economic factors and no trend included in their models.

- Attfield (2005) modelled UK household expenditure for 11 of the 12 COICOP definitions from 1973:q2 to 2003:q2 using the AIDS model. Although, he constructed demographic and income distribution indices and included them in the models, other non-economic factors were not captured.

- Lula and Antille (2007) modelled Swiss expenditure for 1980 to 2005 using the $\mathrm{LES}^{4}$, AIDS and PADS ${ }^{5}$ functional forms. They also aggregated some of the 12 COICOP categories to give eight groups. Again, there was little focus on non-economic factors, although a deterministic trend was included in the LES functional form.

Other studies estimated household expenditure or demand mostly as single equations or sometimes together with some other categories but not necessarily with data

\footnotetext{
${ }^{2}$ Almost Ideal Demand System

${ }^{3}$ Differential consumer demand systems known as Central Bureau of Statistics (CBS)

${ }^{4}$ Linear Expenditure System

${ }^{5}$ Perhaps Adequate Demand system
} 
according to COICOP definitions. Furthermore, almost all did not attempt to capture non-economic factors in the model by using a stochastic trend; the exceptions being Moosa and Baxter (2002), Duffy (2006) and Hunt et al. (2003) who estimate UK alcoholic beverages, UK tobacco and UK energy demand respectively for households using the Structural Time Series Model (STSM).

\section{Estimation Method}

The STSM (see Harvey 1989) is applied to the 12 COICOP categories since this allows for the examination of the relationship between expenditure, income and prices and a stochastic underlying trend. This arguably is important when estimating the elasticities as discussed by Hunt and Ninomiya (2003). The trend captures the systematic non-price and non-income effects that are not easily measured, and therefore difficult to obtain any suitable data.

In addition, the STSM allows for stochastic seasonality so that, along with the stochastic trend, are included in the following long-run expenditure model:

$$
\exp _{t}=\mu_{t}+\lambda_{t}+\pi p_{t}+\tau y_{t}+v_{t} \quad v_{t} \sim N I D\left(0, \sigma_{v}^{2}\right)
$$

where $\exp _{t}$ is household expenditure, $\mu_{t}$ represents the trend component, $\lambda_{t}$ represents the seasonal component, $p_{t}$ is the real price, $y_{t}$ is real household 
disposable income, $\pi$ and $\tau$ are unknown parameters and $v_{t}$ is a random white noise disturbance term. All variables are in natural logarithm.

The trend component $\mu_{t}$ is assumed to have the following stochastic process:

$$
\begin{array}{ll}
\mu_{t}=\mu_{t-1}+\rho_{t-1}+\eta_{t} & \eta_{t} \sim \operatorname{NID}\left(0, \sigma_{\eta}^{2}\right) \\
\rho_{t}=\rho_{t-1}+\xi_{t} & \xi_{t} \sim \operatorname{NID}\left(0, \sigma_{\xi}^{2}\right)
\end{array}
$$

The trend includes the level given by Equation 2 and a slope that is $\rho$, given by Equation 3. $\eta_{t}$ and $\xi_{t}$ are random white noise disturbance terms. The nature of the trend depends on the variances $\sigma_{\eta}^{2}$ and $\sigma_{\xi}^{2}$ (the hyperparameters). To evaluate the estimated models, equation residuals (similar to ordinary regression residuals) and a set of auxiliary residuals are estimated. The auxiliary residuals include smoothed residuals of the error terms for Equation 1, 2 and 3 (known as the irregular, level and slope residuals respectively).

At the extreme $\sigma_{\eta}^{2}=\sigma_{\xi}^{2}=0$ and the model collapses to the following model with a deterministic linear:

$$
\exp _{t}=a+\lambda_{t}+b t+\pi p_{t}+\tau y_{t}+v_{t}
$$

The seasonal component $\lambda_{t}$ has the following stochastic process:

$$
S(L) \lambda_{t}=\omega_{t}
$$


where $\omega_{t} \sim N I D\left(0, \sigma_{\omega}^{2}\right), \mathrm{S}(\mathrm{L})=1+L+L^{2}+L^{3}$ and $L=$ the lag operator. A restricted version of this, $\sigma_{\omega}^{2}=0$ results in $\lambda_{t}$, becoming conventional seasonal dummies.

The Maximum Likelihood (ML) procedure in conjunction with the Kalman filter is used to estimate the following Autoregressive Distributed Lag (ARDL) form of Equation 1, using the software STAMP 6.3 (Koopmans et al., 2000):

$A(L) \exp _{t}=\mu_{t}+\lambda_{t}+B(L) p_{t}+C(L) y_{t}+v_{t}$

where $A(L), B(L)$ and $C(L)$ are polynomial lag operators equal to $1-\alpha_{1} L-\alpha_{2} L^{2}-\ldots-\alpha_{8} L^{8}, \quad 1+\beta_{1} L+\beta_{2} L^{2}+\ldots+\beta_{8} L^{8} \quad$ and $\quad 1+\gamma_{1} L+\gamma_{2} L^{2}+\ldots+\gamma_{8} L^{8}$ respectively. $B(L) / A(L)$ and $C(L) / A(L)$ represent the long-run price and income elasticities respectively. Other variables and parameters are as defined above. This general function is considered initially and the preferred model found by testing down from the over parameterized ARDL model subject to a battery of diagnostic tests. $^{6}$

The following equation represents the estimated version of Equation 6:

$$
\exp _{t}=\hat{\mu}_{t}+\hat{\lambda}_{t}+\hat{B}(L) p_{t}+\hat{C}(L) y_{t}+\hat{A}^{\prime}(L) \exp _{t}+\hat{v}_{t}
$$

\footnotetext{
${ }^{6}$ This includes non-normality, heteroscedasticity, autocorrelation and predictive failure tests. In addition, LR tests are performed for restrictions of a deterministic time trend and deterministic seasonal dummies. For further details, see Hunt and Ninomiya (2003).
} 
where $\hat{A}^{\prime}(L)=\hat{\alpha}_{1} L-\hat{\alpha}_{2} L^{2}-\ldots-\hat{\alpha}_{8} L^{8}$. To estimate the contribution of the trend, seasonality, price and income to expenditure, $\hat{A}^{\prime}(L) \exp$ for lags of expenditure is replaced by Equation 7 until the coefficient of lagged expenditure which appears in right hand side of the equation after replacements approaches zero, so ignorable:

$\exp _{t}=D^{\prime}(L) \hat{\mu}_{t}+E^{\prime}(L) \hat{\lambda}_{t}+\hat{B}^{\prime}(L) p_{t}+\hat{C}^{\prime}(L) y_{t}+F^{\prime}(L) \hat{v}_{t}$

where $D^{\prime}(L)=1+\delta_{1}^{\prime} L+\ldots+\delta_{n}^{\prime} L^{n}, E^{\prime}(L)=1+\varepsilon_{1}^{\prime} L+\ldots+\varepsilon_{n}^{\prime} L^{n}, \hat{B}^{\prime}(L)=1+\beta_{1}^{\prime} L+\ldots+\beta_{n}^{\prime} L^{n}$, $\hat{C}^{\prime}(L)=1+\gamma_{1}^{\prime} L+\ldots+\gamma_{n}^{\prime} L^{n}$ and $F^{\prime}(L)=1+\zeta_{1}^{\prime} L+\ldots+\zeta_{n}^{\prime} L^{n}$. The annual change of Equation 8 is then constructed as follows:

$$
\begin{aligned}
\exp _{t}-\exp _{t-4}= & D^{\prime}(L)\left(\hat{\mu}_{t}-\hat{\mu}_{t-4}\right)+E^{\prime}(L)\left(\hat{\lambda}_{t}-\hat{\lambda}_{t-4}\right)+\hat{B}^{\prime}(L)\left(p_{t}-p_{t-4}\right) \\
& +\hat{C}^{\prime}(L)\left(y_{t}-y_{t-4}\right)+F^{\prime}(\hat{L})\left(\hat{v}_{t}-\hat{v}_{t-4}\right)
\end{aligned}
$$

This therefore attempts to quantify the contributions of the economic drivers (income and price) and Exogenous Non-Economic Factors (hereafter ExNEF) to determining UK household expenditure. ${ }^{7}$ ExNEF therefore accounts for the impact of the unobserved components incorporated in the underlying expenditure trend; ${ }^{8}$ being equal to the annual change in this trend. Consequently, $D^{\prime}(L)\left(\hat{\mu}_{t}-\hat{\mu}_{t-4}\right)$, $E^{\prime}(L)\left(\hat{\lambda}_{t}-\hat{\lambda}_{t-4}\right), \hat{B}^{\prime}(L)\left(p_{t}-p_{t-4}\right), \hat{C}^{\prime}(L)\left(y_{t}-y_{t-4}\right)$ and $F^{\prime}(\hat{L})\left(\hat{v}_{t}-\hat{v}_{t-4}\right)$ are the

\footnotetext{
${ }^{7}$ This work is part of on-going research attempting to quantify the impact of ExNEF on consumer expenditure and demand; see, for example, Chitnis and Hunt (2009a,b) and Broadstock and Hunt (2010).

${ }^{8}$ Previously known as Underlying Energy Demand Trend (UEDT); e.g. Hunt and Ninomiya (2003).
} 
estimated contributions of ExNEF, seasonality, price, income and residuals respectively to the annual change in expenditure $\exp _{t}-\exp _{t-4}$.

\section{Data and Estimation Results}

Data

UK quarterly seasonally unadjusted data for the period 1964:q1 to 2006:q1 from the UK Office for National Statistics (ONS) online database ${ }^{9}$ are used and are in constant terms (reference year 2003). Expenditure implied deflators for each COICOP category, used for real prices, are deflated by total implied deflator to produce relative prices for the same category.

Results

The models are estimated for 1966q1 to 2004:q1, saving 2 years (eight observations) for post-sample prediction tests. The preferred models for each COICOP category are shown in Tables 1(a), (b) and (c) are found by testing down from Equation 6 (with an eight quarters lag on all variables) by eliminating statistically insignificant variables and determining the nature of the trend, but ensuring a range of diagnostics tests are passed.

${ }^{9}$ www.statistics.gov.uk 
\{Tables 1(a), (b) and (c) about here\}

The preferred equations show that almost all models ${ }^{10}$ fit the data well passing all diagnostic tests indicating that there are generally no problems with serial correlation, non-normality or heteroscedasticity. Furthermore, the auxiliary residuals are found to be normal and the model is stable as indicated by the post sample predictive failure tests. The estimated price and income elsaticities are inelastic in both the short and the long run - except for 'recreation and culture' where the income elasticity is elastic in the long run. ${ }^{11}$

Likelihood Ratio (LR) tests for all preferred equations find that imposing the restriction of a deterministic trend ${ }^{12}$ is rejected so that the underlying expenditure trends are non-linear, generally increasing for most of the categories over the estimation period; hence, shifting the expenditure demand curve to the right (with price and income constant). However, the underlying expenditure trends are generally decreasing for 'alcoholic beverages and tobacco, narcotics' and very

\footnotetext{
${ }^{10}$ The exceptions being 'recreation and culture' that suffers from autocorrelation despite some experimentation with different specifications and/or dummy variables.

${ }^{11}$ For 'housing, water, electricity, gas and other fuels' and 'health' both the income and price coefficients are insignificant. 'Education’ expenditure has a negative income coefficient (giving negative income elasticities in both the short and long run).

${ }^{12}$ By restricting the variance of the level and/or the slope to be zero.
} 
stochastic for 'clothing and footwear' and 'furnishings; household equipment \& routine maintenance of the house' ('furnishings' hereafter), shifting the expenditure demand curve upwards and downwards at different times (ceteris paribus). LR-tests also indicate that imposing the restriction of deterministic seasonality is rejected for all categories except for 'communication' and 'education'.

\{Figs 1 to 6 about here\}

The estimated relative contributions of price, income, ExNEF, and seasonality for 1980:q1 to 2006:q1, derived from Equation 9, are given in Figures 1-12. ${ }^{13}$ These show that in general, seasonality has a relatively small effect on expenditure whereas for some sectors ExNef has a relatively large impact. For 'food and non-alcoholic beverages', 'clothing and footwear', 'furnishings, 'transport', 'recreation and culture', 'restaurants and hotels' and' miscellaneous goods and services' ExNEF contributes considerably to the change in expenditure relative to price and income. This reflects the stochastic nature of the underlying expenditure trend and implies that the effect of ExNEF should not be ignored, in particular for 'food and nonalcoholic beverages’ expenditure.

\footnotetext{
${ }^{13}$ Charts showing the estimated underlying expenditure trend and seasonality for each sector can be found in Chitnis and Hunt (2009a). Note, all charts use the preferred models re-estimated over the whole period, up to and including 2006:q1.
} 
In the case of 'housing, water, electricity, gas and other fuels', 'health', ‘communication' and 'education' categories, ExNEF has a large impact on expenditure changes; much higher than the contribution from price and income. This highlights the importance of considering the non-economic factors when considering what drives expenditure in these groups.

\section{Summary and Conclusion}

Using the STSM it is shown that the contribution from ExNEF to annual changes in expenditure is important relative to the contribution from the economic drivers. For the majority of the UK 12 COICOP categories the relative contribution from ExNEF is estimated to be very high; in particular for 'housing, water, electricity, gas and other fuels’, ‘health', ‘communication’ and ‘education'. Therefore, assuming policy makers do not wish to reduce the rate of economic growth as a way to curtail the growth in expenditure the message is clear. For categories with large ExNEF contributions to driving expenditure changes, in addition to economic incentives (such as taxes) other policies attempting to influence lifestyles might need to be considered if they wish to restrain future expenditure to achieve sustainable consumption. However, for categories with low or no contribution from ExNEF, the primary policy option for reducing expenditure, which are price inelastic, is to increase prices significantly; although this might have social consequences that need 
to be considered. Therefore, a challenge remains for the UK government on how to bring about significant behaviour change in such categories of expenditure.

\section{Acknowledgements}

This work is part of the interdisciplinary research group RESOLVE ${ }^{14}$ funded by the ESRC (Award Reference: RES-152-25-1004) and their support is gratefully acknowledged. We would also like to thank members of RESOLVE for many discussions about the work, in particular David Broadstock, Angela Druckman and Tim Jackson. Of course, the authors are responsible for any remaining errors.

\section{References}

Attfield, C. L. F. (2005) A time series aggregate demand model with demographic and income distribution indices, mimeo, University of Bristol, www.efm.bris.ac.uk/ecca/ESRC_Demand_Indices/Aggregate_Demand.pdf accessed on 29/04/2010.

Broadstock, D. C. and Hunt, L. C. (2010) Quantifying the Impact of Exogenous NonEconomic Factors on UK Transport Oil Demand, Energy Policy, 38, 1559-1565.

Chitnis, M. and Hunt, L.C. (2009a) Modelling UK Household Expenditure: Economic Versus Non-economic Drivers, RESOLVE Working Paper Series, 07-09, University of Surrey.

Chitnis, M. and Hunt, L. C. (2009b) What drives the change in UK household energy expenditure and associated CO2 emissions, economic or non-economic factors?, RESOLVE working paper series, 08-09, University of Surrey.

\footnotetext{
${ }^{14}$ www.surrey.ac.uk/resolve/.
} 
Duffy, M. (2006) Tobacco consumption and policy in the United Kingdom, Applied Economics, 38, 1235-1257.

Harvey, A.C. (1989) Forecasting, Structural Time Series Model and the Kalman Filter, Cambridge, UK, Cambridge University Press.

Harvey, A.C. and Koopman, S.J. (1992) Diagnostic checking of unobserved-components time series models, Journal of Business and Economic Statistics, 10, 377-389.

Hunt, L.C., Judge G. and Ninomiya Y. (2003) Underlying trends and seasonality in UK energy demand: a sectoral analysis, Energy Economics, 25, 93-118.

Hunt, L.C. and Ninomiya Y. (2003) Unravelling trends and seasonality: a structural time series analysis of transport oil demand in the UK and Japan, Energy Journal, 24, 63-96.

Koopman S.J., Harvey, A.C., Doornik J.A. and Shephard N. (2000) Stamp: Structural Time Series Analyser, Modeller and Predictor, London, Timberlake Consultants Press.

Lula, J and Antille A. (2007) Estimation of private consumption functions for Switzerland, The Fifteenth World Inforum Conference, Trujillo, Spain, September, 10-16.

Moosa, I. A. and Baxter, J. L. (2002) Modelling the trend and seasonals within an AIDS model of the demand for alcoholic beverages in the United Kingdom, Journal of Applied Econometrics, 17, 95-106.

Slevanathan, S. and Slevanathan E. A. (2004) Empirical regularities in South African consumption patterns, Applied Economics, 36, 2327-2333. 
Table 1a: Estimated STSM expenditure functions for the UK 1964q1-2004q1

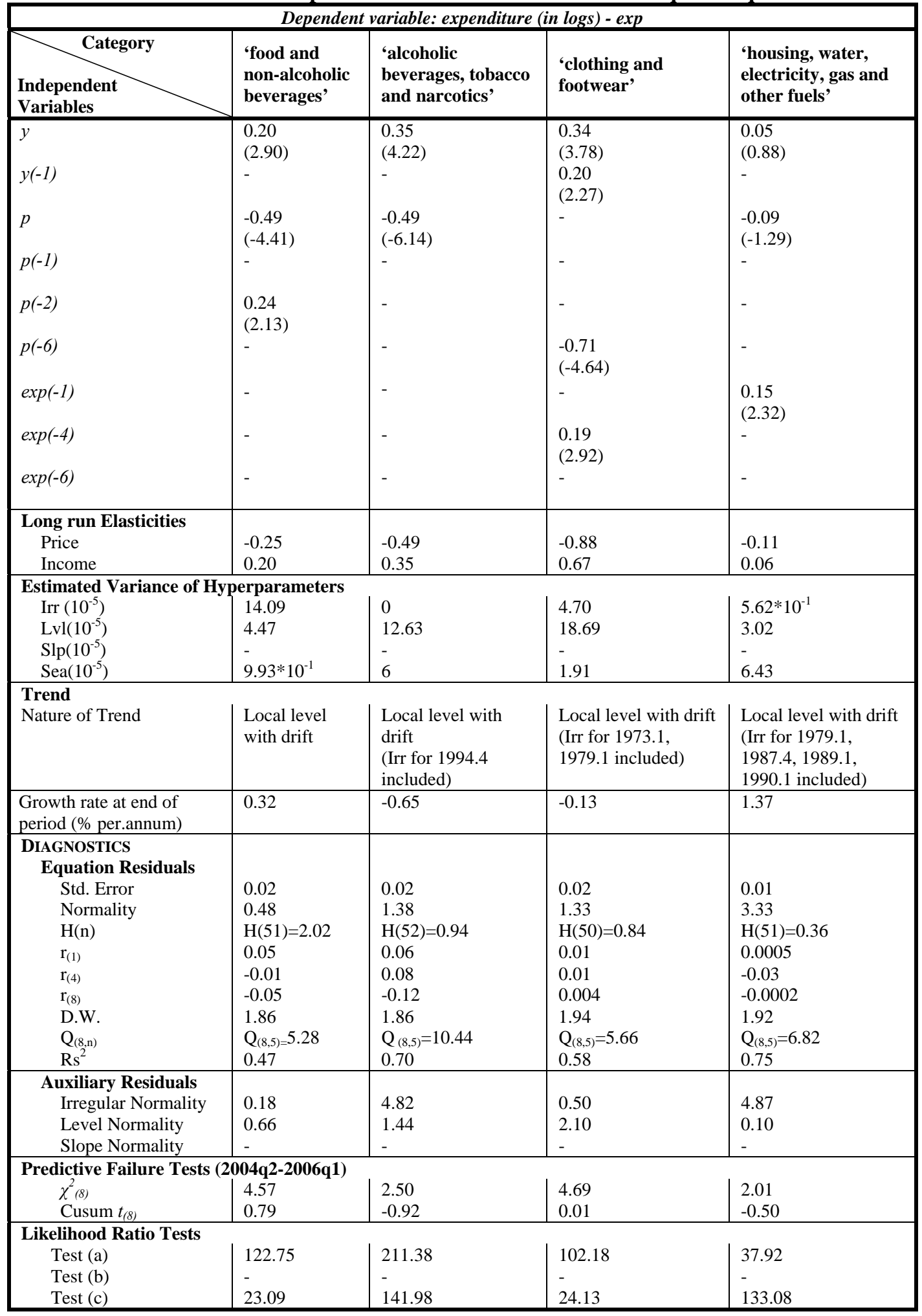

Notes for Table 1a:

exp, y and p represent expenditure, income and the real price of each category (all in logs). Irr represent intervention dummies. 
t-statistics are given in parenthesis.

The restrictions imposed for the $L R$ - test are: a) fixed level, b) fixed slope, c) fixed seasonal.

Normality is the Doornik-Hansen statistic approximately distributed as $X^{2}{ }_{(2)}$.

$\mathrm{H}(\mathrm{n})$ is the test for heteroscedasticity, approximately distributed as $F_{(n, n)}$.

$r_{(1)}, r_{(4)}$ and $r_{(8)}$ are the serial correlation coefficients at the $1^{\text {st }}, 4^{\text {th }}$ and $8^{\text {th }}$ lags respectively, approximately distributed at

$\mathrm{N}(0,1 / \mathrm{T})$.

DW is the Durbin Watson statistic.

$\mathrm{Q}_{(8, \mathrm{n})}$ is the Box-Ljung Q-statistic based on the first $\mathrm{n}$ residuals autocorrelation; distributed as $X_{(n)}^{2}$.

$\mathrm{R}^{2}$ is the coefficient of determination.

$X^{2}{ }_{(8)}$ is the post-sample predictive failure test. The Cusum $t$ is the test of parameter consistency, approximately distributed as the t-distribution.

$5 \%$ probability level is considered for significance.

Following Harvey and Koopman (1992), where necessary, appropriate dummies are included in the models for outliers and structural breaks. 
Table 1b: Estimated STSM expenditure functions for the UK 1964q1-2004q1

\begin{tabular}{|c|c|c|c|c|}
\hline \multicolumn{5}{|c|}{ Dependent variable: expenditure (in logs) - exp } \\
\hline $\begin{array}{l}\text { Independent } \\
\text { Variables }\end{array}$ & 'furnishings' & 'health’ & 'transport' & 'communication' \\
\hline $\bar{y}$ & 0.67 & 0.08 & - & - \\
\hline$y(-1)$ & - & - & 0.67 & 0.12 \\
\hline & & & $(4.42)$ & $(2.02))$ \\
\hline$p$ & -0.79 & -0.16 & -0.97 & -0.13 \\
\hline & $(-3.54)$ & $(-1.01)$ & $(-4.15)$ & $(-3.48)$ \\
\hline$p(-1)$ & & & 0.80 & - \\
\hline$p(-2)$ & - & - & & \\
\hline$p(-6)$ & - & & - & - \\
\hline $\exp (-1)$ & $\begin{array}{l}0.19 \\
(3.24)\end{array}$ & - & - & - \\
\hline $\exp (-4)$ & & & - & $\begin{array}{l}0.29 \\
(5.31)\end{array}$ \\
\hline $\exp (-6)$ & - & $\begin{array}{l}0.18 \\
(2.29)\end{array}$ & - & - \\
\hline \multicolumn{5}{|l|}{ Long run Elasticities } \\
\hline Price & -0.98 & -0.20 & -0.17 & -0.18 \\
\hline Income & 0.83 & 0.10 & 0.67 & 0.17 \\
\hline \multicolumn{5}{|c|}{ Estimated Variance of Hyperparameters } \\
\hline $\operatorname{Irr}\left(10^{-5}\right)$ & 2.30 & 17.78 & 8.34 & 5.50 \\
\hline $\operatorname{Lvl}\left(10^{-5}\right)$ & 19.96 & 29.80 & 42.55 & 29.21 \\
\hline $\operatorname{Slp}\left(10^{-5}\right)$ & & & & - \\
\hline Sea $\left(10^{-5}\right)$ & 9.98 & 4.61 & 15.00 & - \\
\hline \multicolumn{5}{|l|}{ Trend } \\
\hline Nature of Trend & $\begin{array}{l}\text { Local level with } \\
\text { drift (Irr 1968.1, } \\
\text { 1973.1, 1973.2, } \\
\text { 1979.2 included) }\end{array}$ & $\begin{array}{l}\text { Local level with } \\
\text { drift }\end{array}$ & $\begin{array}{l}\text { Local level with } \\
\text { drift (Irr 1968.1, } \\
\text { 1974.1, 1979.2 } \\
\text { included) }\end{array}$ & $\begin{array}{l}\text { Local level with } \\
\text { drift (Irr 1971.1, } \\
\text { 1982.4, 1986.2 } \\
\text { included) }\end{array}$ \\
\hline $\begin{array}{l}\text { Growth rate at end of } \\
\text { period (\% per annum.) }\end{array}$ & -0.14 & 1.98 & 1.56 & 3.98 \\
\hline \multicolumn{5}{|l|}{ DIAGNOSTICS } \\
\hline Equation Residuals & & & & \\
\hline Std. Error & 0.03 & 0.03 & 0.04 & 0.02 \\
\hline Normality & 1.75 & 3.02 & 5.39 & 2.81 \\
\hline $\mathrm{H}(\mathrm{n})$ & $\mathrm{H}(51)=0.71$ & $H(50)=0.62$ & $H(51)=0.37$ & $H(51)=0.98$ \\
\hline$r_{(1)}$ & 0.02 & 0.02 & 0.01 & 0.02 \\
\hline$r_{(4)}$ & 0.07 & 0.05 & 0.07 & 0.06 \\
\hline$r_{(8)}$ & -0.03 & -0.01 & 0.01 & -0.05 \\
\hline D.W. & & & & \\
\hline $\begin{array}{l}\mathrm{Q}_{(8, \mathrm{n})} \\
\mathrm{Rs}^{2}\end{array}$ & $\begin{array}{l}\mathrm{Q}_{(8,5)}=5.82 \\
0.63\end{array}$ & $\begin{array}{l}\mathrm{Q}_{(8,5)}=2.49 \\
0.59\end{array}$ & $\begin{array}{l}\mathrm{Q}_{(8,5)}=5.55 \\
0.71\end{array}$ & $\begin{array}{l}\mathrm{Q}_{(8,6)}=3.57 \\
0.58\end{array}$ \\
\hline \multicolumn{5}{|l|}{ Auxiliary Residuals } \\
\hline Irregular Normality & 4.10 & 0.05 & 3.05 & 0.71 \\
\hline Level Normality & 4.80 & 1.17 & 2.01 & 1.63 \\
\hline Slope Normality & - & - & - & - \\
\hline \multicolumn{5}{|c|}{ Predictive Failure Tests (2004q2-2006q1) } \\
\hline$\chi^{2}(8)$ & 14.46 & 3.36 & 1.53 & 8.25 \\
\hline Cusum $t_{(8)}$ & -1.00 & -0.38 & -0.55 & -1.20 \\
\hline \multicolumn{5}{|l|}{ Likelihood Ratio Tests } \\
\hline Test (a) & 67.64 & 160.10 & 211.89 & 170.22 \\
\hline Test (b) & & & & - \\
\hline Test (c) & 95.01 & 61.60 & 104.66 & - \\
\hline
\end{tabular}

Notes for Table 1b: see notes to Table 1a. 
Table 1c: Estimated STSM expenditure functions for the UK 1964q1-2004q1

\begin{tabular}{|c|c|c|c|c|}
\hline \multicolumn{5}{|c|}{ Dependent variable: expenditure (in logs) - exp } \\
\hline Category & $\begin{array}{l}\text { 'recreation and } \\
\text { culture' }\end{array}$ & 'education’ & $\begin{array}{l}\text { 'restaurants and } \\
\text { hotels' }\end{array}$ & $\begin{array}{l}\text { 'miscellaneous } \\
\text { goods and } \\
\text { services' }\end{array}$ \\
\hline $\begin{array}{l}y \\
y(-1) \\
p \\
p(-1) \\
p(-2) \\
p(-6) \\
\exp (-1) \\
\exp (-4) \\
\exp (-6)\end{array}$ & $\begin{array}{l}0.27 \\
(3.17) \\
0.19 \\
(2.20) \\
-0.51 \\
(-2.81) \\
- \\
- \\
\\
0.45 \\
(2.61) \\
0.25 \\
(3.45) \\
- \\
-\end{array}$ & $\begin{array}{l}-0.12 \\
(-2.28) \\
- \\
-0.45 \\
(-7.63) \\
0.37 \\
(5.78) \\
- \\
- \\
0.74 \\
(13.74) \\
- \\
-\end{array}$ & $\begin{array}{l}0.34 \\
(3.48) \\
0.28 \\
(2.78) \\
-0.71 \\
(-4.17) \\
- \\
- \\
- \\
0.22 \\
(3.08) \\
- \\
-\end{array}$ & $\begin{array}{l}0.37 \\
(4.40) \\
- \\
-0.69 \\
(-3.24) \\
- \\
- \\
0.46 \\
(2.28) \\
0.25 \\
(4.49) \\
- \\
-\end{array}$ \\
\hline $\begin{array}{l}\text { Long run Elasticities } \\
\text { Price } \\
\text { Income } \\
\end{array}$ & $\begin{array}{l}-0.24 \\
1.84 \\
\end{array}$ & $\begin{array}{l}-0.11 \\
-0.16 \\
\end{array}$ & $\begin{array}{l}-0.91 \\
0.79\end{array}$ & $\begin{array}{l}-0.23 \\
0.49\end{array}$ \\
\hline $\begin{array}{l}\text { Estimated Variance of } \mathbf{H} \\
\operatorname{Irr}\left(10^{-5}\right) \\
\operatorname{Lvl}\left(10^{-5}\right) \\
\operatorname{Slp}\left(10^{-5}\right) \\
\operatorname{Sea}\left(10^{-5}\right) \\
\end{array}$ & $\begin{array}{l}\text { perparameters } \\
2.72 \\
13.74 \\
- \\
3.42 \\
\end{array}$ & $\begin{array}{l}9.37 \\
11.67 \\
- \\
- \\
\end{array}$ & $\begin{array}{l}4.69 \\
17.87 \\
- \\
5.44 \\
\end{array}$ & $\begin{array}{l}11.40 \\
- \\
1.39 \\
2.14\end{array}$ \\
\hline $\begin{array}{l}\text { Trend } \\
\text { Nature of Trend }\end{array}$ & $\begin{array}{l}\text { Local level with } \\
\text { drift } \\
\text { (Irr 1990.1 } \\
\text { included) }\end{array}$ & $\begin{array}{l}\text { Local level } \\
\text { with drift } \\
\text { (Irr 1970.4, } \\
\text { 1971.2, 1972.1 } \\
\text { included) }\end{array}$ & $\begin{array}{l}\text { Local level with } \\
\text { drift } \\
\text { (Irr 1993.1 } \\
\text { included) }\end{array}$ & $\begin{array}{l}\text { Smooth trend } \\
\text { (Irr 1986.1, 1987.4, } \\
1990.1 \text { included) }\end{array}$ \\
\hline $\begin{array}{l}\text { Growth rate at end of } \\
\text { period (\% per annum) }\end{array}$ & 2.85 & 1.14 & 0.63 & -0.73 \\
\hline $\begin{array}{l}\text { DIAGNOSTICS } \\
\text { Equation Residuals } \\
\text { Std. Error } \\
\text { Normality } \\
\mathrm{H}(\mathrm{n}) \\
\mathrm{r}_{(1)} \\
\mathrm{r}_{(4)} \\
\mathrm{r}_{(8)} \\
\text { D.W. } \\
\mathrm{Q}_{(8, \mathrm{n})} \\
\mathrm{Rs}^{2}\end{array}$ & $\begin{array}{l}0.02 \\
4.73 \\
H(50)=1.09 \\
0.03 \\
0.10 \\
-0.11 \\
1.92 \\
Q_{(8,5)}=15.85 \\
0.56\end{array}$ & $\begin{array}{l}0.02 \\
5.72 \\
H(52)=0.88 \\
-0.007 \\
0.006 \\
0.04 \\
1.99 \\
Q_{(8,6)}=1.69 \\
0.57\end{array}$ & $\begin{array}{l}0.02 \\
4.48 \\
\mathrm{H}(51)=0.89 \\
-0.004 \\
0.01 \\
-0.04 \\
2.00 \\
\mathrm{Q}_{(8,5)}=5.05 \\
0.61\end{array}$ & $\begin{array}{l}0.02 \\
2.41 \\
\mathrm{H}(50)=1.49 \\
-0.01 \\
0.03 \\
-0.16 \\
2.02 \\
\mathrm{Q}_{(8,5)}=5.46 \\
0.64\end{array}$ \\
\hline $\begin{array}{c}\text { Auxiliary Residuals } \\
\text { Irregular Normality } \\
\text { Level Normality } \\
\text { Slope Normality } \\
\end{array}$ & $\begin{array}{l}5.45 \\
1.07 \\
- \\
\end{array}$ & $\begin{array}{l}5.69 \\
2.12 \\
- \\
\end{array}$ & $\begin{array}{l}5.38 \\
3.03 \\
- \\
\end{array}$ & $\begin{array}{l}2.29 \\
- \\
1.12 \\
\end{array}$ \\
\hline $\begin{array}{l}\text { Predictive Failure Tests } \\
\chi_{(8)}^{2} \\
\text { Cusum } t_{(8)} \\
\end{array}$ & $\begin{array}{l}\text { 004q2-2006q1) } \\
12.15 \\
0.17 \\
\end{array}$ & $\begin{array}{l}1.20 \\
-0.55\end{array}$ & $\begin{array}{c}4.24 \\
-0.13 \\
\end{array}$ & $\begin{array}{l}6.87 \\
0.11 \\
\end{array}$ \\
\hline $\begin{array}{l}\text { Likelihood Ratio Test } \\
\text { Test (a) } \\
\text { Test (b) } \\
\text { Test (c) }\end{array}$ & $\begin{array}{l}44.65 \\
- \\
96.41\end{array}$ & $\begin{array}{l}59.55 \\
- \\
-\end{array}$ & $\begin{array}{l}41.13 \\
- \\
101.69\end{array}$ & $\begin{array}{l}- \\
67.68 \\
84.40\end{array}$ \\
\hline
\end{tabular}

Notes for Table 1c: see notes to Table 1a. 


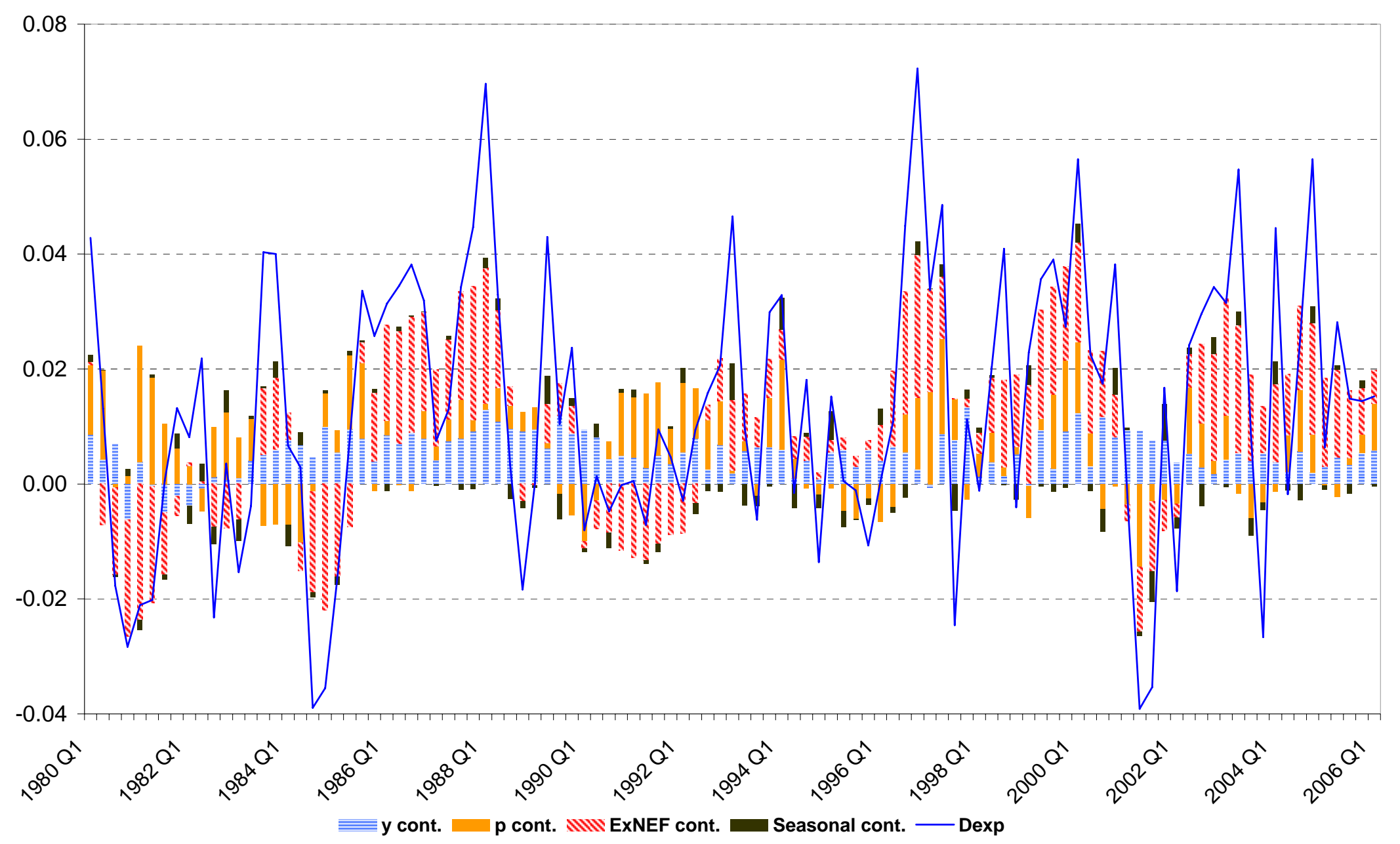

Fig. 1. Contribution of income, price, ExNEF and seasonality to changes in 'food and non-alcoholic beverages' expenditure 


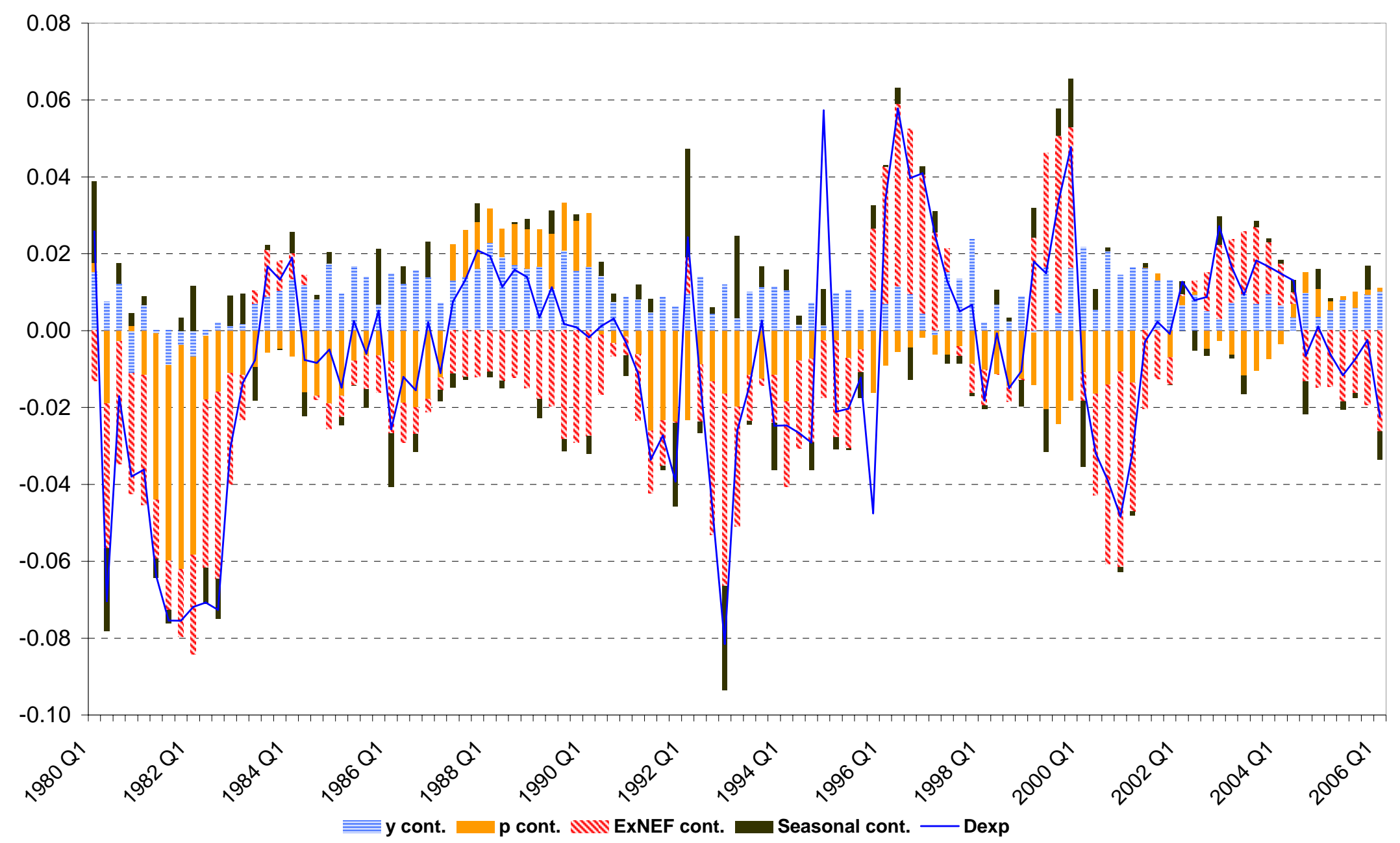

Fig. 2. Contribution of income, price, ExNEF and seasonality to changes in 'alcoholic beverages and tobacco' expenditure 


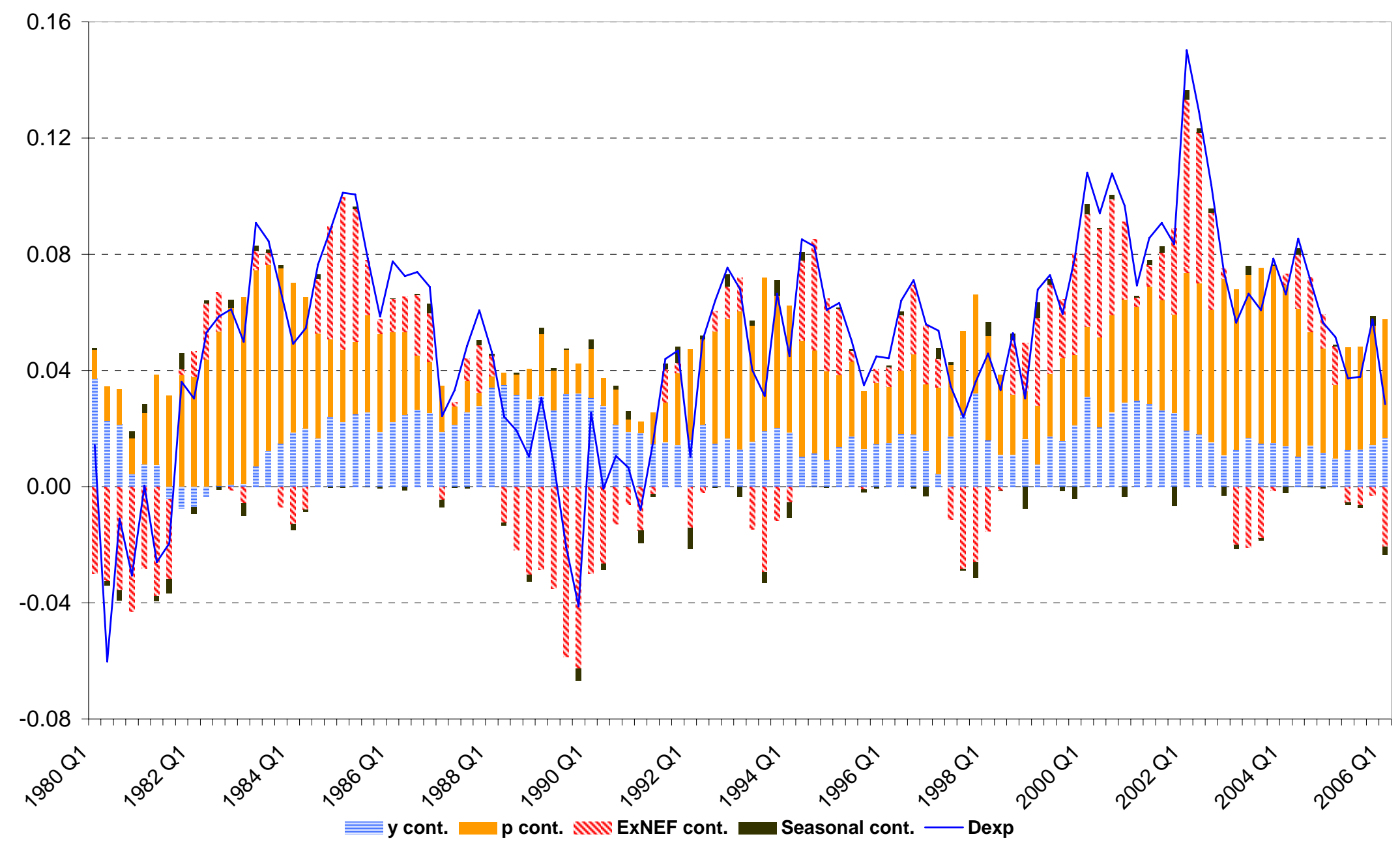

Fig. 3. Contribution of income, price, ExNEF and seasonality to changes in 'clothing and footwear' expenditure 


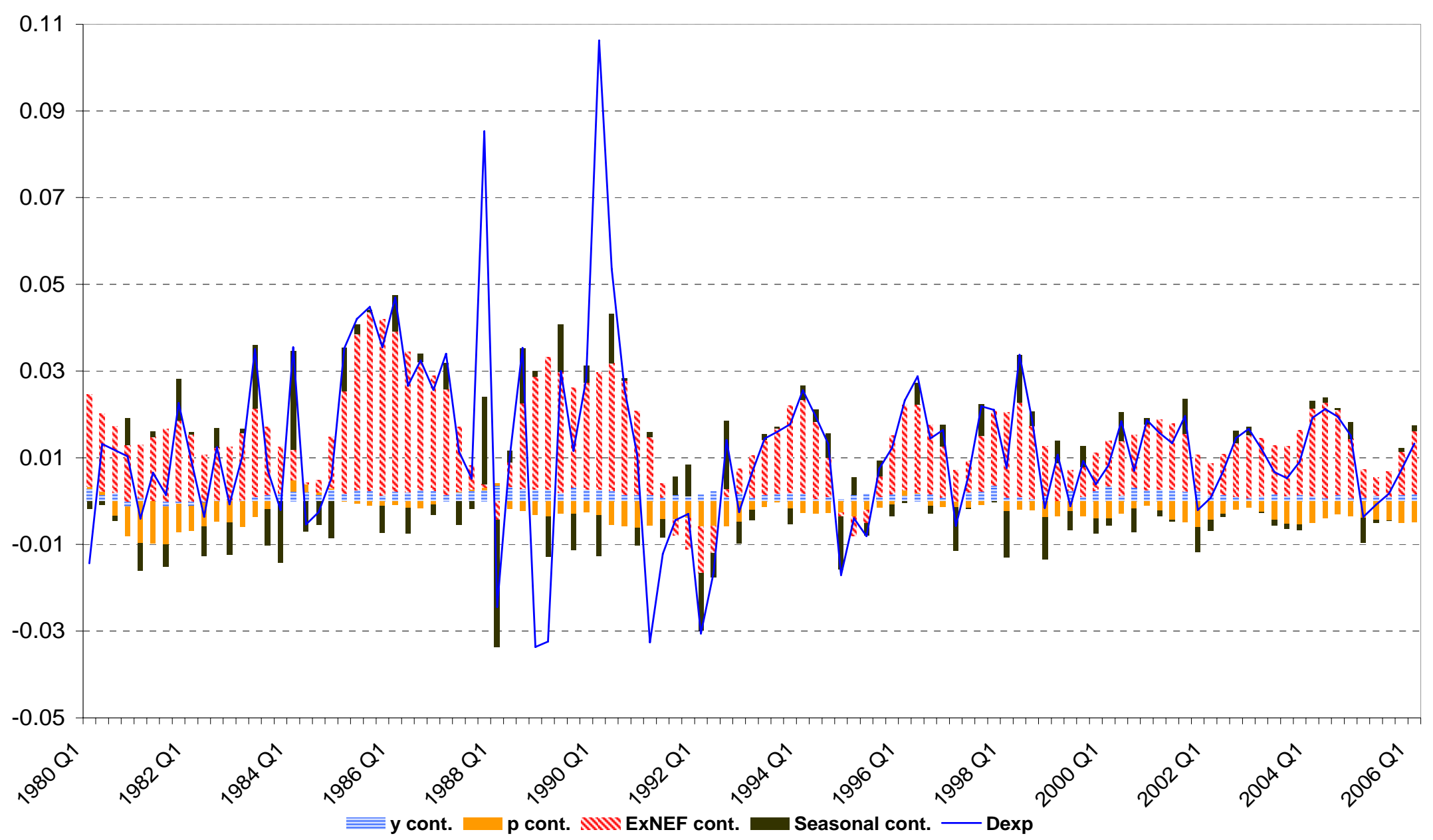

Fig. 4. Contribution of income, price, ExNEF and seasonality to changes in 'housing, water, electricity, gas and other fuels' expenditure 


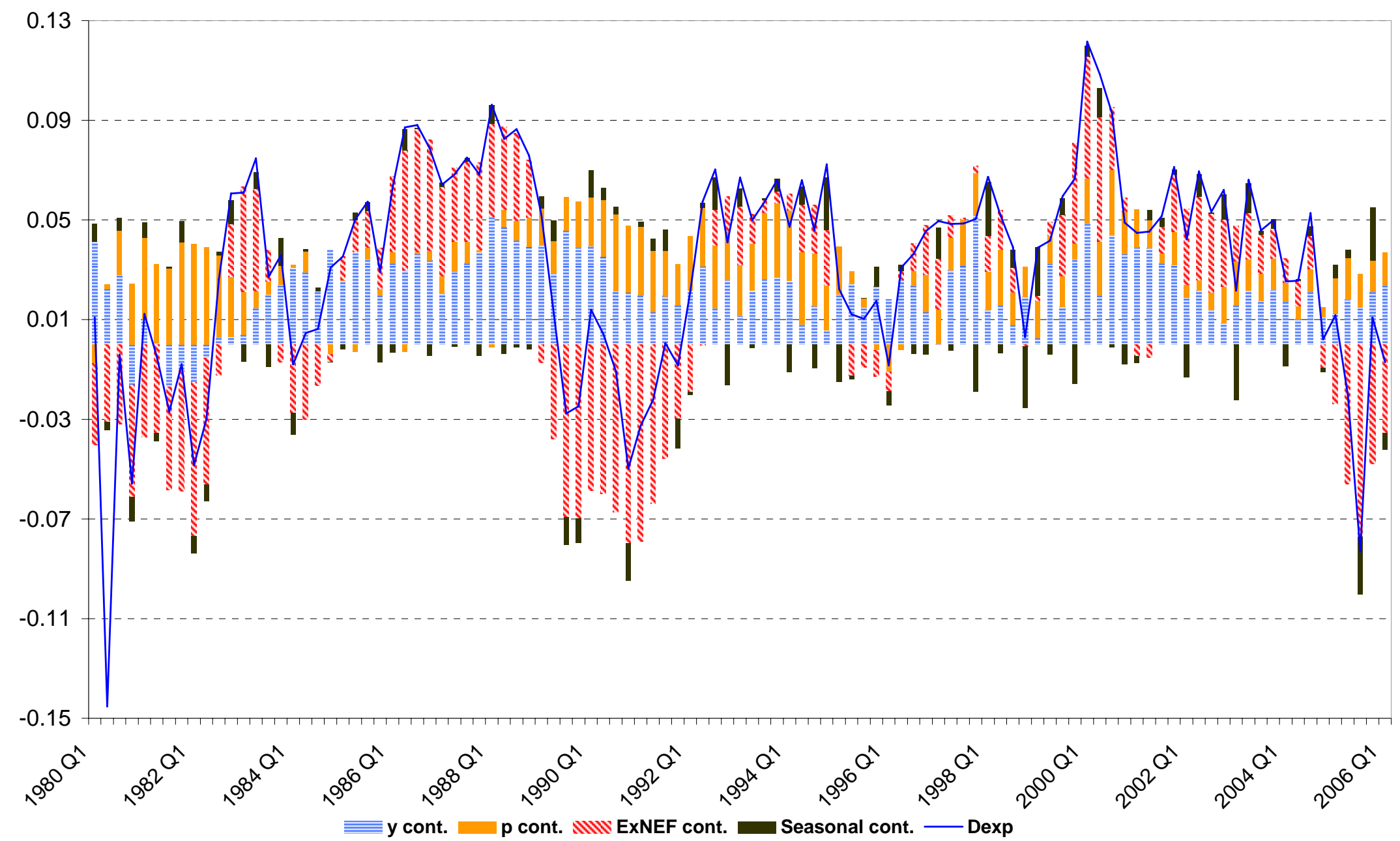

Fig. 5. Contribution of income, price, ExNEF and seasonality to changes in 'furnishings' expenditure 


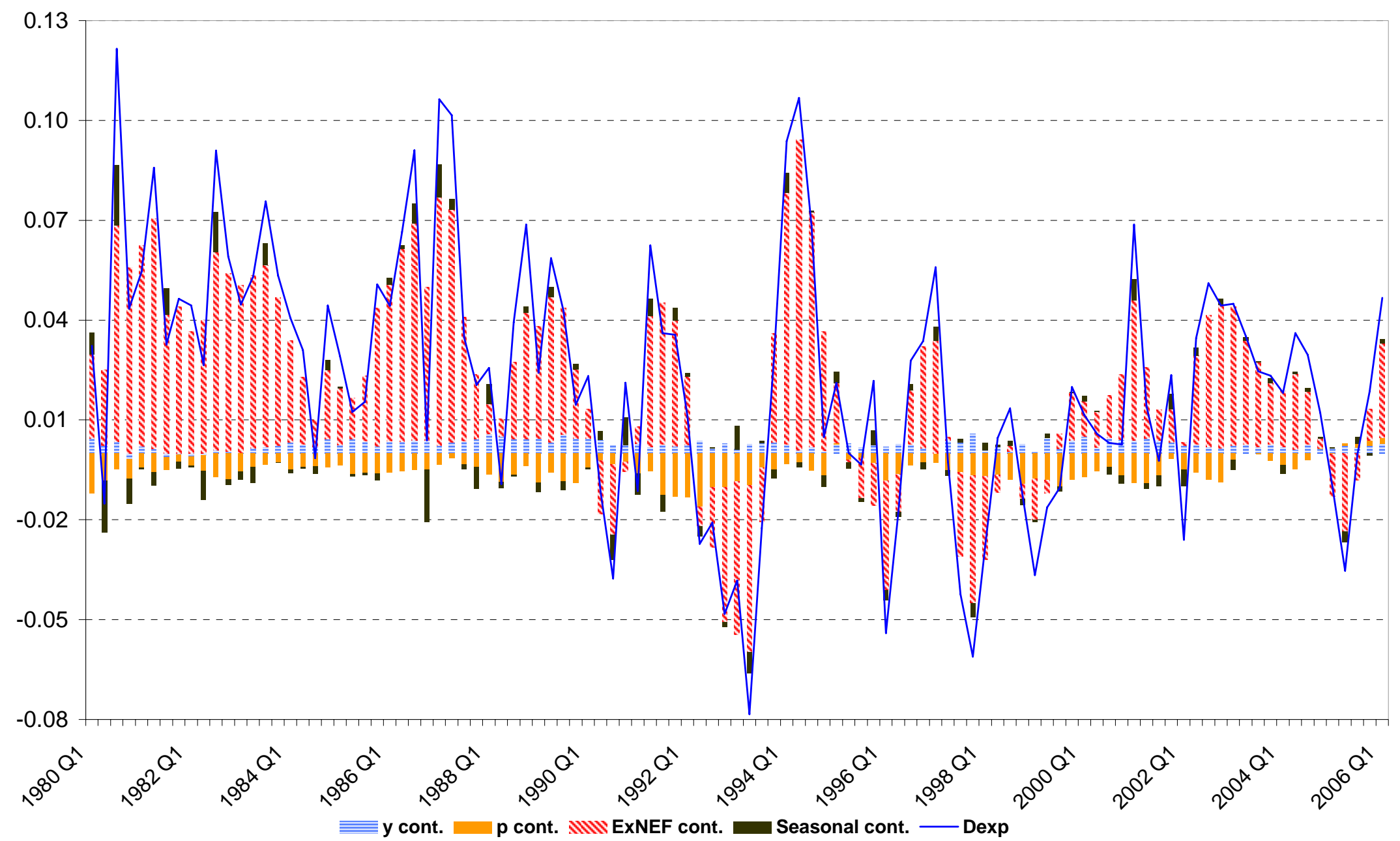

Fig. 6. Contribution of income, price, ExNEF and seasonality to changes in 'health' expenditure 


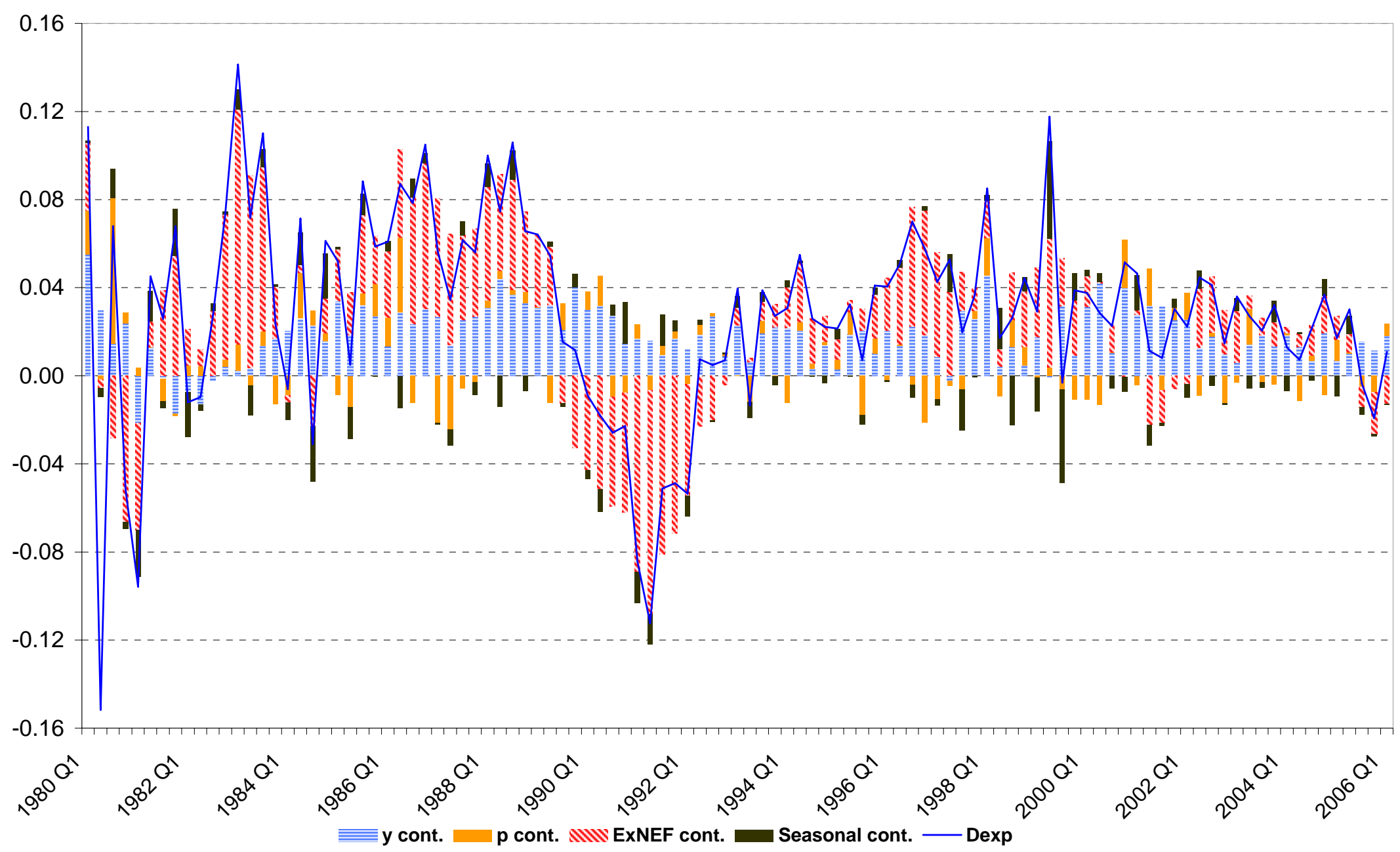

Fig. 7. Contribution of income, price, ExNEF and seasonality to changes in 'transport' expenditure 


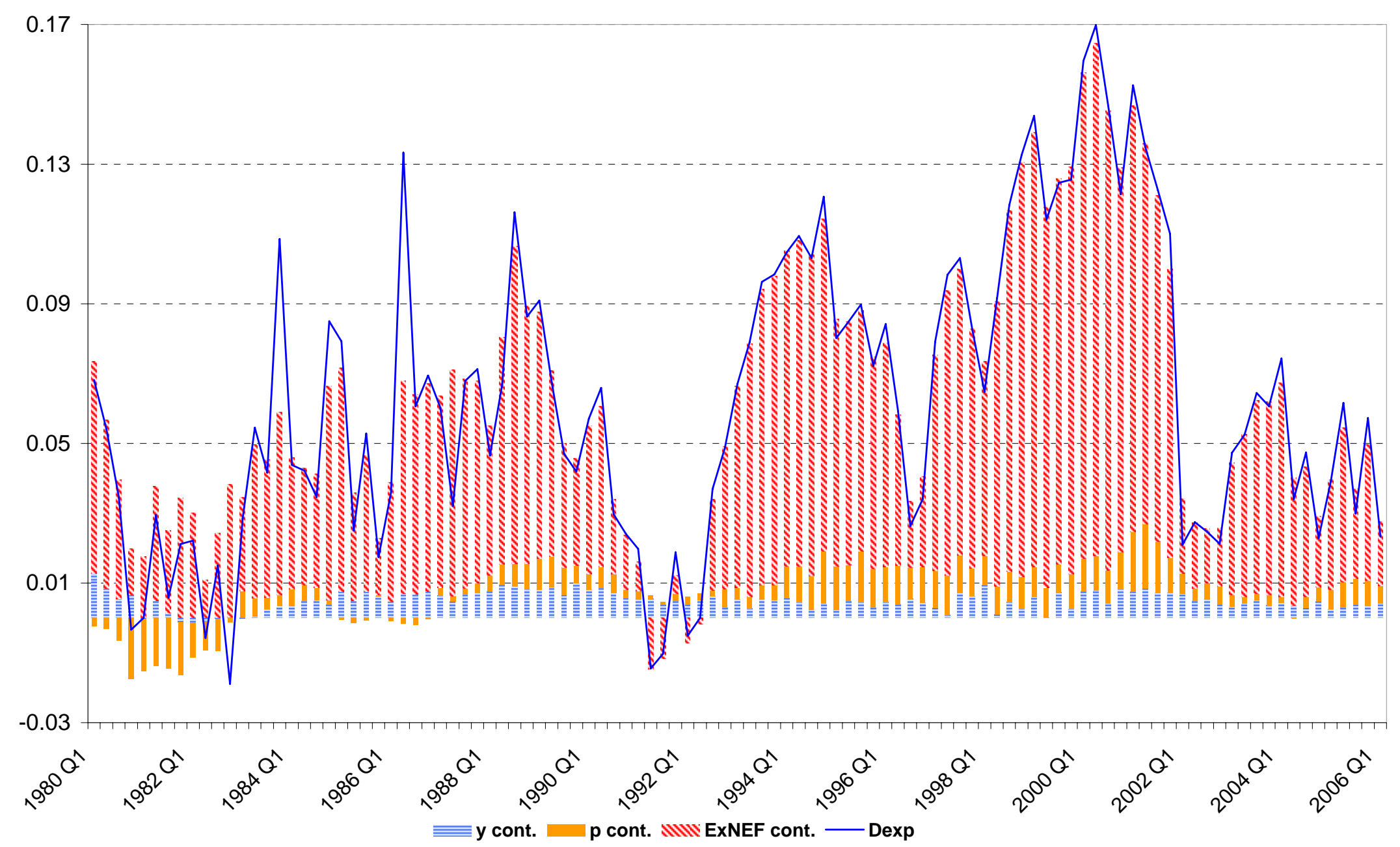

Fig. 8. Contribution of income, price, ExNEF and seasonality to changes in 'communication' expenditure 


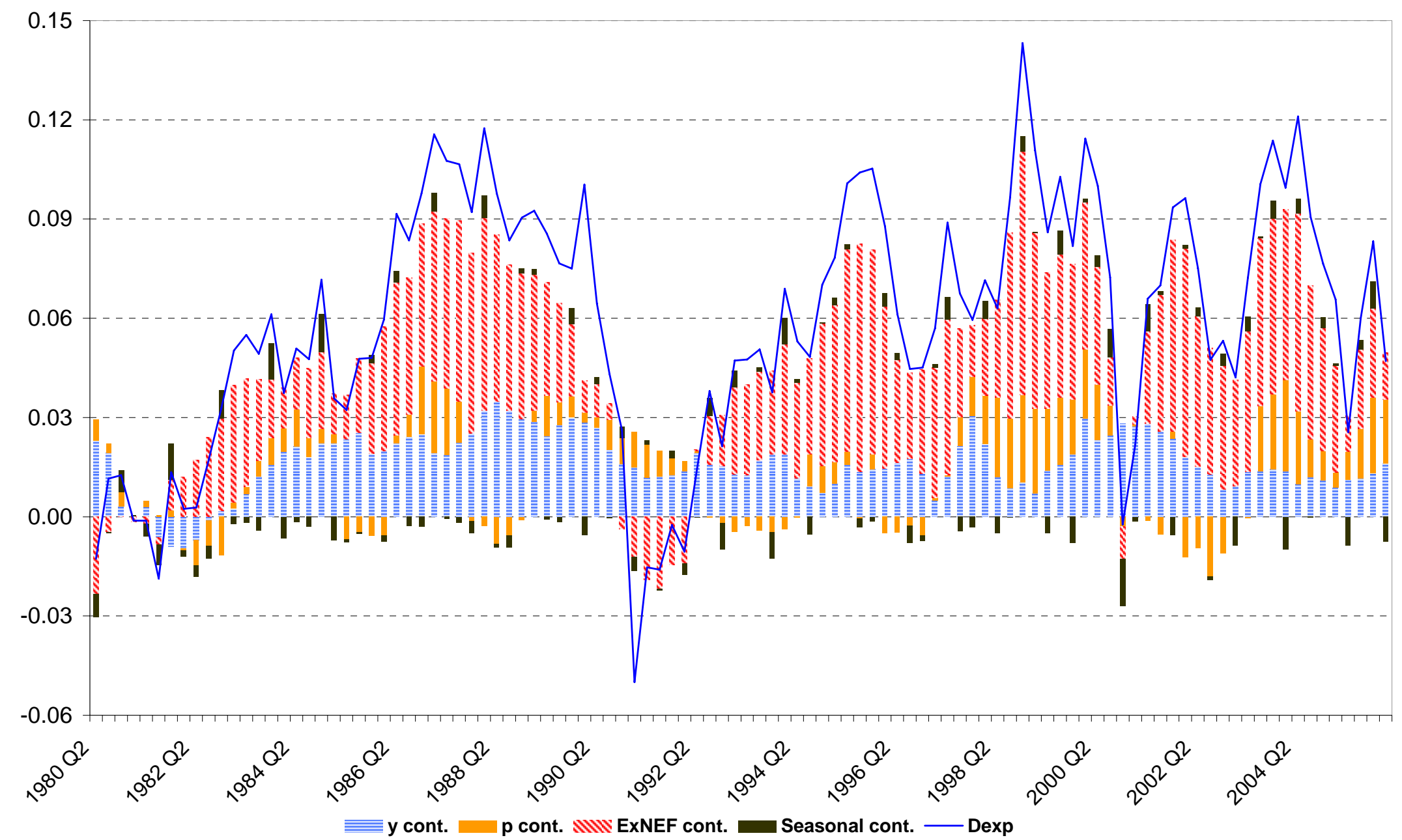

Fig. 9. Contribution of income, price, ExNEF and seasonality to changes in 'recreation and culture' expenditure 


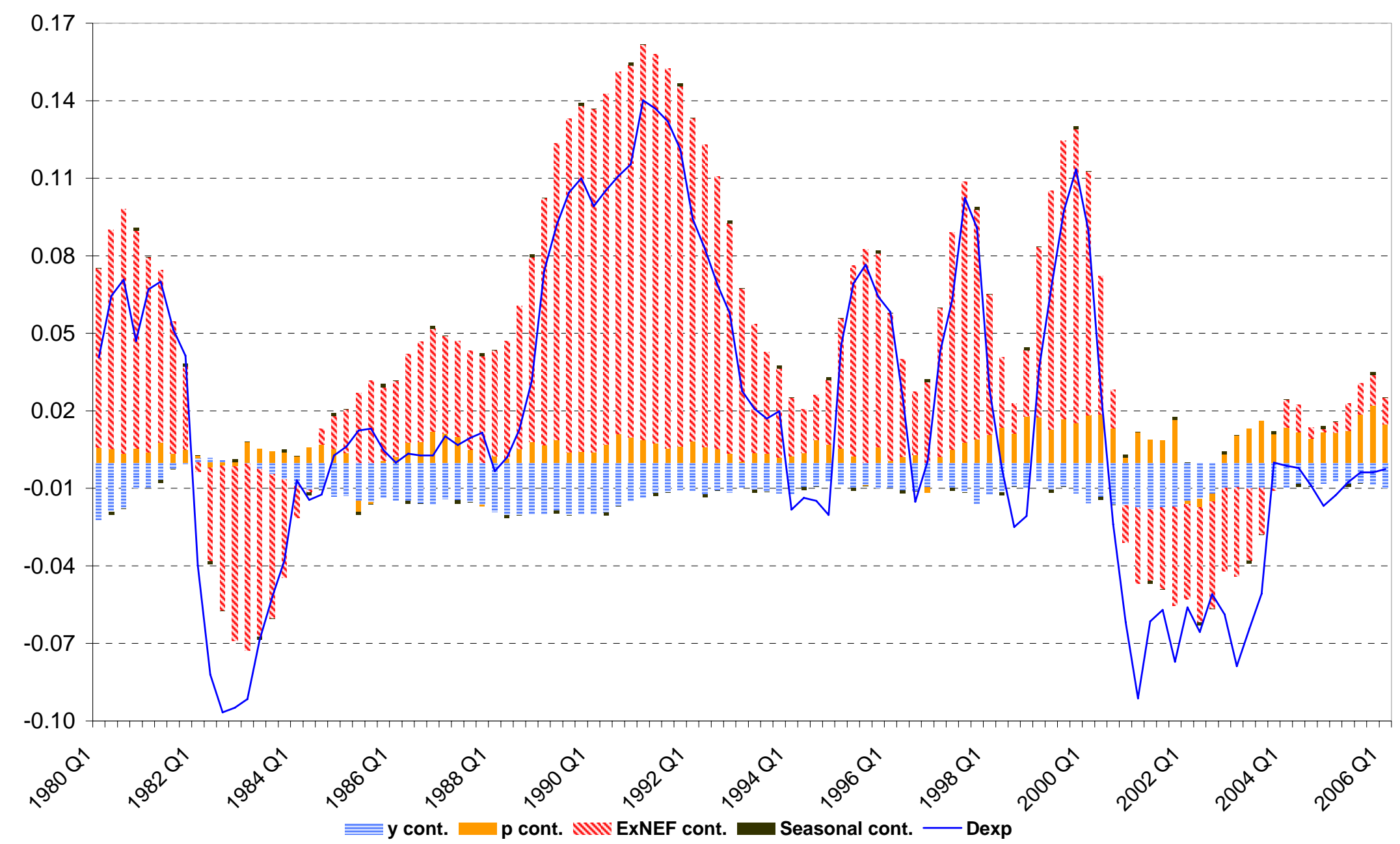

Fig. 10. Contribution of income, price, ExNEF and seasonality to changes in 'education' expenditure 


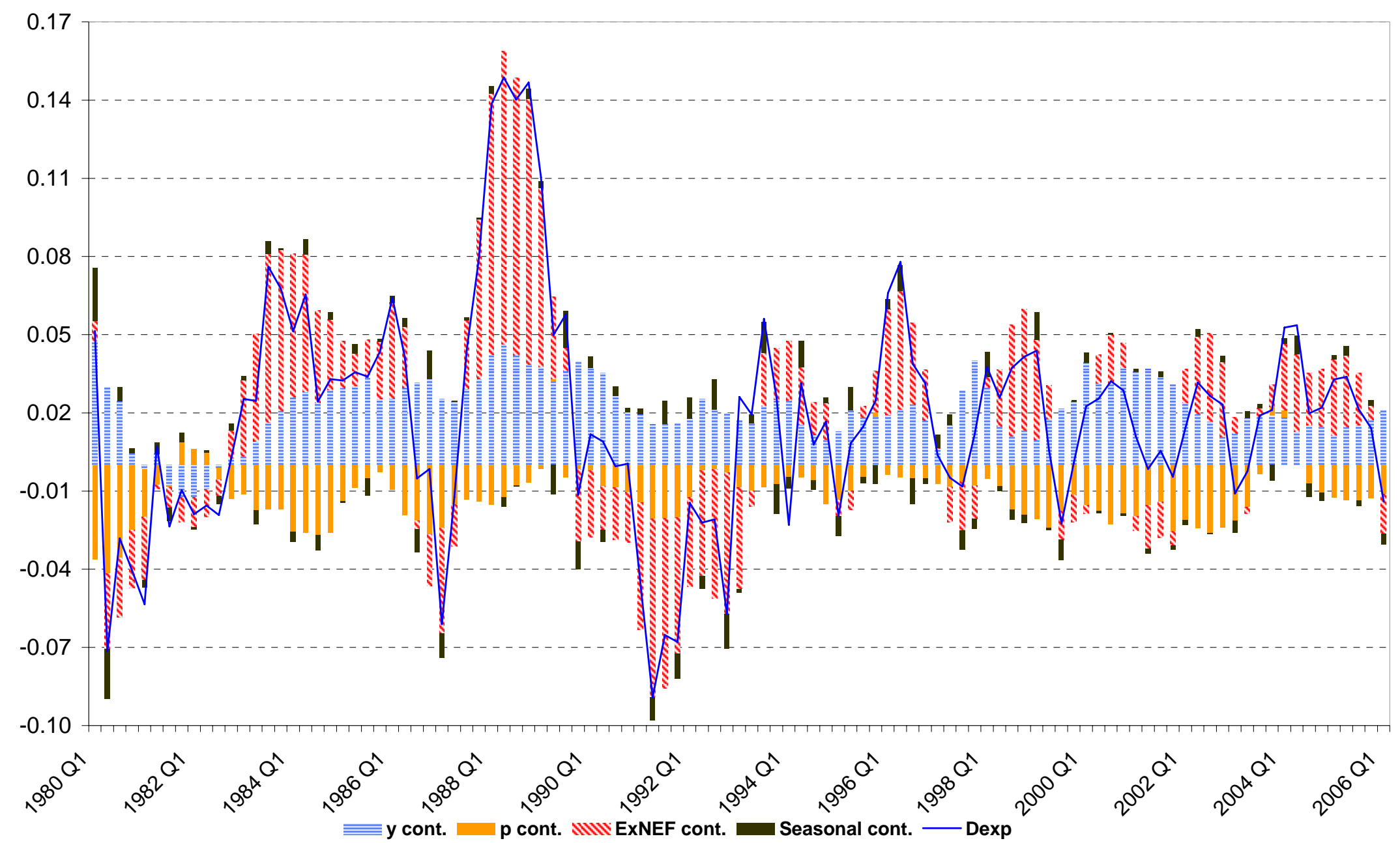

Fig. 11. Contribution of income, price, ExNEF and seasonality to changes in 'restaurant and hotels' expenditure 


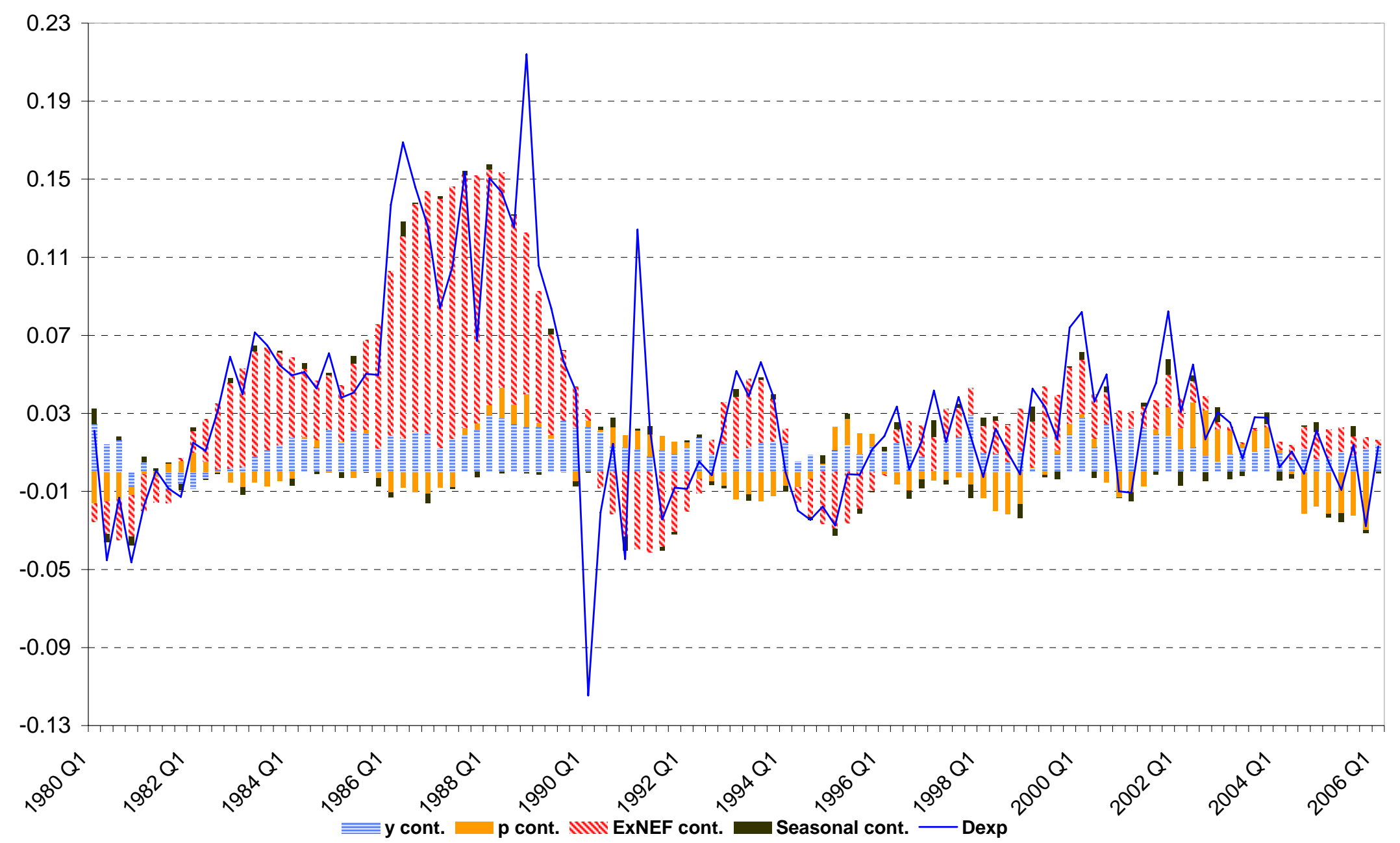

Fig. 12. Contribution of income, price, ExNEF and seasonality to changes in 'miscellaneous goods and services' expenditure 